\title{
Precarious domesticities: Energy vulnerability among urban young adults
}

Link to publication record in Manchester Research Explorer

\section{Citation for published version (APA):}

Bouzarovski, S., Petrova, S., Kitching, M., \& Baldwick, J. (2013). Precarious domesticities: Energy vulnerability among urban young adults. In Energy Justice in a Changing Climate: Social Equity and Low-Carbon Energy (pp. 30-45). Zed Books.

\section{Published in:}

Energy Justice in a Changing Climate: Social Equity and Low-Carbon Energy

\section{Citing this paper}

Please note that where the full-text provided on Manchester Research Explorer is the Author Accepted Manuscript or Proof version this may differ from the final Published version. If citing, it is advised that you check and use the publisher's definitive version.

\section{General rights}

Copyright and moral rights for the publications made accessible in the Research Explorer are retained by the authors and/or other copyright owners and it is a condition of accessing publications that users recognise and abide by the legal requirements associated with these rights.

\section{Takedown policy}

If you believe that this document breaches copyright please refer to the University of Manchester's Takedown Procedures [http://man.ac.uk/04Y6Bo] or contact uml.scholarlycommunications@manchester.ac.uk providing relevant details, so we can investigate your claim.

\section{OPEN ACCESS}




\title{
Precarious domesticities: Energy vulnerability among urban young adults ${ }^{1}$
}

\author{
Stefan Bouzarovski (corresponding author: stefan.bouzarovski@manchester.ac.uk) \\ Saska Petrova \\ Matthew Kitching \\ Josh Baldwick
}

\section{Introduction}

Even though recent years have seen the publication of a wide body of research on the broad-level relationships between fuel poverty, energy efficiency, poor housing and health (see, for example, Rudge and Nicol 1999; Healy and Clinch 2004) it still remains unclear how these linkages operate at the level of everyday life in the home. What is more, the articulation of the underlying systemic causes of energy vulnerability within the grain of the city is poorly understood, particularly in relation to the rising importance of scientific agendas that see such dynamics as the product of social justice issues of distribution, procedure and recognition (Walker and Day 2012). This becomes especially pronounced once the focus is moved away from issues of energy deprivation among older people - a group that, its objective difficulties notwithstanding, has traditionally attracted the greatest amount of political support, public visibility and assistance from the state - onto more transient and precarious populations.

The almost complete absence of research of fuel poverty among urban young adults exemplifies such research lacunae. While a selected set of social formations that already include this group - especially lowincome families with children, and young single parents - have attracted some public, academic and policy attention in the UK fuel poverty debate, households consisting exclusively of young adults, most of whom live in rented accommodation, have generally been excluded from relevant fora (see, for instance, Baker et al 2003). This situation may have adverse consequences, as for example, more than 10 per cent of households where the oldest person is younger than 24 are likely to fall in fuel poverty, while households living in private rented accommodation - most common among young people and young people - are twice more likely to suffer from fuel poverty compared to all other households (poverty.org.uk). The importance of studying fuel poverty patterns among young people is further underscored by their specific consumption practices, as this group's low awareness about energy conservation and efficiency measures in the home is well documented in the literature (Clugston and Calder 1999). Furthermore, a significant body of research has found that economic inequalities among young people at school-leaving age are on the rise, while their opportunities for earning an independent income are decreasing (Katz 2004).

This chapter provides some initial insights into the social, spatial and economic underpinnings of fuel poverty ${ }^{2}$ among young people. We aim to expose the precarious and transient nature of their energy vulnerability patterns, emphasising that issues of recognition are central to understanding and addressing this group's susceptibility to domestic energy deprivation. The evidence presented in the chapter is based on quantitative and qualitative research in the Birmingham district of Bournbrook, which houses one of the largest concentrations of flat-sharing young people (mostly students) living in rented accommodation in the country. We explore the extent to which such individuals suffer from fuel poverty as a result of moving out of the parental home, while identifying some of the main housing and social features of households in this group. The chapter also hints at some of the wider mechanisms through which the emergence of fuel poverty among such households is contingent on everyday life practices, behaviours and attitudes. This includes, but is not limited to issues such as residential energy efficiency, household energy needs, the ability to understand and access energy assistance, and relationships with landlords.

\footnotetext{
${ }^{1}$ The authors of this report thank the Cheshire Lehmann Fund for their generous support towards the background research that led to this study. Additional funding was provided by the Durham Energy Institute, the Ministry of Education of the Czech Republic, and the EPSRC via the ADMIER project. We are grateful to Benjamin Hayman and Dr Kathrin Hörschelmann for their contributions in setting the conceptual framework and gathering some of the data that led to this chapter.

${ }^{2}$ We understand fuel poverty in wider terms, as a condition when a household lacks socially- and materiallynecessitated energy services in the home (based on Buzar 2007).
} 


\section{Housing young adults in the UK: unresolved urban and energy policy questions}

When talking about young adults moving into independent accommodation, it should be noted that this demographic is characterised by specific housing demand requirements, which set it apart from other social and age groups (Rugg et al 2000). However, there has been insufficient research on the subject, making it difficult to draw any conclusions on how the UK meets the housing needs of young adults, particularly students. This is despite the fact that over the past 50 years - and in line with the majority of industrialised countries during the post-war period - the UK has seen a consistent growth in student numbers. The expected possession of a university degree has now become commonplace, and despite a commitment of a succession of governments to a growth in higher education opportunities, very little attention has been paid to the housing consequences of expanded student numbers.. In particular, there has been a growing reliance on the private rented sector due to the fact that the student population increase in cities has, in general, surpassed the ability of higher educational institutions to accommodate this group. It has also been recognised that student renting compromises what might be termed a 'niche market' (Rugg et al 2000): one in which supply has become adapted to meet the needs of a specific, specialised group, and displays a reluctance to meet demand from another source.

The market has a particular characteristic in terms of accommodation type, letting arrangements and type of landlord: letting to a student household is materially different from letting to other types of tenant (Rugg et al 2000). For example, although student incomes are low, their access to loans means that they are usually able to meet regular rent instalments and thus sidestep difficulties that landlords might anticipate and experience with the processing of payments. The flexibility of student and young adult households places them at an advantage when compared with some other household types that may have more exact specifications (Slater 2002), such as families requiring a garden for their children or wanting to be in a catchment area of good local schools; older couples who may need assistance using the stairs; or couples with young children who may need properties with adequate access for a pram. In contrast with all these groups, student or young adult households can be any size, and have limited specialised requirements. Another aspect of the student (and young adult) housing market is the ability of such households to adapt to any type of property, with perhaps the only requirement being that the dwelling is furnished. This has led to a situation where homes whose original layouts are often not fit for this purpose have been rented out to students.

One of the most marked consequences of the expansion of the private rented sector among students and young adults has been the tendency for large numbers of such households to live in concentrated urban pockets (Rugg et al 2000). The clear geographic definition of their housing market has made it easy for landlords seeking to make their investment to pinpoint the most appropriate locations in which to buy property. Where pressure for student accommodation is becoming acute, it is likely that properties that come onto the owner-occupied market will be quickly bought up by student market landlords. Student demand has thus been monopolising the rental sector of particular urban districts (Smith and Holt 2007), often leading to the phenomenon of 'student ghettoisation': traditional local retailing has been replaced by an unusual concentration of fast food restaurants, cafeterias, takeaways, accommodation agencies, second-hand dealers in furniture and kitchen appliances, leisure services and amusement arcades, and discount supermarkets. Other changes have affected the local pubs and clubs, most of which have been re-orientated to the student and youth market (ibid).

One frequent issue relating to student and young flat-sharing accommodation is the poor quality of the properties in which many such households live. The image of 'student squalor' is markedly persistent, and a number of studies of housing conditions among this group have underlined the incidence of dampness, poor electrical safety, overcrowding, and inadequate facilities (Humphrey and McCarthy 1997; Nicholson and Wasoff 1989). The poor energy efficiency of rented properties has been one of the key factors behind the poor living conditions in such properties - particularly in relation to issues such as damp and mould.

In order to address some of these issues, the government has introduced the 'Landlord's Energy Saving Allowance' (LESA) so as to provide tax incentives for landlords who make energy saving improvements to their properties. It allows landlords to claim up to $£ 1,500$ against tax every year, and can be claimed for properties rented out in the UK and abroad. LESA can be claimed for costs of buying and installing certain energy saving products for properties that are being rent out, based on actual expenditure, including: cavity wall and loft insulation, solid wall and floor insulation, draught proofing and hot water system insulation. 
The allowance can claimed up to 1 April 2015, when its availability will end. Its scope was recently extended - initially the funding applied per building, which has now been changed to 'per dwelling'. This means that a landlord who makes significant energy changes with a property divided into flats may be eligible for an allowance for each flat. It remains unclear, however, to what extent the LESA has helped alleviate fuel poverty. In general, experts have argued that households living in privately rented housing are arguably the hardest group to reach, while also living in some of the worst insulated and oldest homes (with 45 per cent built pre-1919, see Boardman 2010).

Also of relevance in this context are measures introduced as part of the 2011 Energy Act, and the Green Deal. Having established that the rental sector has the largest proportion of least energy efficient homes (5.8 percent belong to the category of poorly $\mathrm{G}$ rated properties as opposed to 3.4 percent in owner-occupied homes) it recently became mandatory that from 2018, private landlords will need to ensure that their properties either meet a minimum energy efficiency standard, or have installed the maximum package of measures under the Green Deal. The broader implications of such policies on the nature of the housing stock and migration patterns within it, however, remain unclear.

These contingencies underline the urgent need for studying young people's vulnerability to fuel poverty. Not only can such an endeavour produce new policy relevant insights into this pressing problem - especially in terms of identifying the kinds of measures that can help raise awareness of energy conservation and fuel poverty among them - but it can also potentially create a new knowledge base about the circumstances of young people more generally, relevant to researchers and activists in the domains of social welfare, environment, housing policy and youth empowerment.

\section{Overarching trends in the case study area}

Our study area comprised the western part of the Selly Oak ward, corresponding to seven census areas (Lower Layer Super Output Areas; LSOAs). The index of multiple deprivation places almost all of these locations among the worst 40 per cent in the country. One of the largest contributors to this ranking is the 'Barriers to Housing and Services' component of the index, which categorises most of the study area in the UK's worst quartile. The study area scores particularly poorly on the 'Income Deprivation Affecting Children Index 2010', which is of special relevance to the circumstances of young people included in our study. A similar situation can be found in the case of the 2007 Child Well Being index (CWI): Nearly all of the LSOAs that constitute the study area are among the 10 per cent most deprived in the UK according to this measure, with one area's rank being an exceptional 2.49 per cent. One of the main contributors to the CWI of these areas is the housing domain of the index, which places most of them among the 5 per cent most deprived areas in the UK (one LSOA is even in the top 0.31 per cent). Overall, therefore, this means that the study area has been characterised by moderate to high levels of multiple deprivation, partly as a result of inadequate housing and low incomes - the main causal factors of fuel poverty.

Quantitative and qualitative methods were employed to achieve the research aims outlined in the introduction. The questionnaire surveys involved 75 randomly-selected households (containing a total of 320 individuals) undertaken in February 2012. The questionnaire covered the household features and housing history of the participants, their current income, dwelling conditions, thermal comfort circumstances and practices, as well as energy consumption behaviours and patterns. In addition, semi-structured interviews were undertaken in order to explore some of the questions from the survey in further depth, so as to detect the nuances in household behaviours and expectations.

A total of 36 households from Bournbrook were involved in the qualitative part of the research. This included detailed energy diaries, as well as energy consumption and temperature measurements undertaken during one- to two-week periods in 2011 and 2012. The diaries operated on a self-reported basis, including information about the state and use of various energy services in the home, and associated everyday life practices. The diaries and interviews were followed up by thermal camera imaging that allowed us to obtain a better sense of the energy efficiency of the built fabric of the surveyed homes. This method produces an image of the thermal energy emitted by any object (Meola and Carlomagno 2004).

Some of the data from the questionnaire survey made it immediately clear that many of the surveyed households are receiving inadequate energy services in the home. The sample was largely composed of 
students; 68 per cent of the surveyed households consisted mainly of flat-sharers in this category. A large part of the surveyed population in the sample suffered from perceived inadequate levels of warmth in the home (see Figure 1). The poor energy efficiency of the surveyed buildings might have contributed to this, alongside the relatively low incomes of the interviewees: approximately 50 per cent of the surveyed households stated that they have been cutting back on appliance use to save energy, and approximately 25 per cent of the surveyed households thought their landlords did not take adequate care of the home (see Figure 2).

Many of the individuals we interviewed did not live in properties that were well maintained: common problems included ill-fitting windows and poor wall insulation. This was confirmed by the thermal images that we took, as well as the fact that a large part of the surveyed individuals thought that the rooms on the top floor were significantly colder than the rest of the house - thus possibly indicating that there was a loss of useful heat through the roof (see Figure 3); also, a significant portion (over 50 per cent) reported having mould and condensation in their house. Nevertheless, approximately 40 per cent of the surveyed households 'strongly agreed' that their house had double glazing, and an overwhelming majority felt that they were not living in fuel poverty (see Figure 4). The results from the survey thus indicated that many of the participants may not be aware that they are living in fuel poverty and poorly insulated homes.

\section{$<$ Insert Figures 1, 2, 3 and 4 about here $>$}

\section{Experiences of fuel poverty}

As pointed out above, the quantitative surveys in our study were supplemented with in-depth qualitative investigations, which helped pinpoint some of the everyday articulations and experiences of fuel poverty among households in the study area. In the two sections that follow, we explore these themes in further detail - using a limited number of examples from the evidence base - so as to foreground the broader dynamics of social and infrastructural vulnerability encountered by the surveyed households.

The two graphs below (Figures 5 and 6) provide a summary of the internal temperature and diary data from two rooms within one house. One data logger was located in the living room, and another in the top floor bedroom. Both demonstrated similar results and trends, with peaks corresponding to heating use as indicated. However, the living room data indicates a generally higher temperature throughout the period (averaging $19.4^{\circ} \mathrm{C}$ ) which can be explained with the aid of the diaries, which contain frequent comments such as: 'all ate between $6.30 \mathrm{pm}$ and $7.30 \mathrm{pm}$ and then all stayed in the living room until 10.30pm'.

In contrast, less time was spent, and fewer people resided, in the bedroom, causing a lower average temperature $\left(16.3^{\circ} \mathrm{C}\right)$. Still, the highest temperature peaks could be seen in the bedroom data. This is once again detailed in the diaries where one participant describes 'working from home during the afternoon' during both of the periods when the highest peaks were registered. Such graphs are more correlated to the times of heating use and show far more reactivity; possibly due to the household not opening windows at all in order to keep a more steady base temperature, which is then further modified by the heating.

\section{$<$ Insert Figures 5 and 6 about here $>$}

This house on the whole used $189.08 \mathrm{kWh}$ of gas throughout the week-long study (roughly costing them just over $£ 8$, according to their energy bill - £2 each), which breaks down to approximately $47.2 \mathrm{kWh}$ of gas per person over a week. This appears high when compared to a student house of similar size (depicted in Figures 7 and 8 ), where participants used a total of $126.05 \mathrm{kWh}$ over the week; when considering the number of residents this broke down to only $25.21 \mathrm{kWh}$ per person and only cost approximately $£ 6$ (ca. $£ 1.20$ per person) for the week. The observed gap, however, seems less surprising when the results of the diaries are taken into account. The house in Figures 5 and 6 averages three hours of heating use per day, as a result of which Figure 6 shows a relatively consistent heating pattern and stable temperatures. In contrast, the second house used only 2 hours of heating throughout the study - in interviews its residents claimed to be 'tightfisted' with their energy use due to the fact that 'they had little money and refused to spend it on bills'. This refusal to use the heating was reflected in the thermal images of the building. 
The highest level of heating use for a privately rented house is shown in Figure 7 below. The data here is again very responsive to heating use, with definite peaks and troughs in line with the information about energy use indicated in the diaries. However, for such a high rate heating use - on average nearly 4 hours per day - the average temperature was the lowest of all of the student houses studied $\left(15.8^{\circ} \mathrm{C}\right.$ - again well below any of the WHO's recommended temperatures). The participants in this house used $189.08 \mathrm{kWh}$ of gas during the study week, or $63.03 \mathrm{kWh}$ per person - the highest $\mathrm{kWh}$ consumption per person in any of the private rented homes studied. While the diaries showed that no windows were opened during the study period, the thermal imaging indicated a high rate of energy leakage in the built fabric.

\section{$<$ Insert Figure 7 about here $>$}

Despite such examples of lower temperatures, many of the interviewees continued to insist that fuel poverty was not a problem for them. Personal choice, university grants, support from parents and the fact they aren't around during particular months were all highlighted as reasons why they felt that this condition did not impact upon them:

Interviewer: You don't think it is a problem?

Emily: No I don't spend 10 per cent of anything on my energy bills. Like I said it was expensive for us but like we must have spent, I don't know, $£ 200$ not even that $\$ 150$ and by the time we have left this house we will have spent $\$ 250$ and per year I get a ridiculous amount of money like 9 grand it's not a ridiculous amount of money but it is still quite a lot for a student.

Interviewer: You say it is not an issue for you but on the graph over the week there was only one time that the living room was 21 degrees, but it doesn't bother you?

Jemma: Erm... I think I should be Ok, because my parents help me out quite a lot, so I am going ... well I don't know yet what they are going to do but I think they are going to pay for my rent and then I am going to pay for bills.

Other participants felt that fuel poverty was an issue for them and consequently affected how they used their accommodation. Some commented how particularly cold rooms would be used less, and interestingly, some discussed how they allow themselves to get cold because they don't want to cause an argument with those on tighter budgets who can't afford any more heating:

Christine: And well I haven't lived here over the summer but I assume that, with the flat roof it might absorb some heat. But I can't turn on the heating without discussing it with the girls so there have been times when I have been really cold.

Interviewer: So though you may be cold, you just put up with it?

Chloe: Yeah, it is a case of though I may be cold I don't want to do anything that goes against the house decision.

Several participants mentioned that because they cannot afford heating during the day they would go to university or to other people's houses to conduct their daily activities:

Interviewer: Why do you go to uni more this year?

Anna: Warmth probably [laugh], I mean it would just be too expensive to have the heating on during the day as well, so it is much warmer and you can get far more work done as well. It is generally better all round to go to uni.

Gemma 2: Well, at first at the beginning of the term when it was quite cold in the house, I started going to the library more. And as well like I thought, you usually get more work done and stuff like that, but the main reason was, it is too cold in the house so I will just go to the library.

Nicole 2: ... Also, like I go to Rey's house when I get cold, like the other day, so I thought I would go to his house because it will be warm and work there because it will be a lot warmer.

Overall, many of the interviewees did not understand what 'fuel poverty' meant; even when the concept was explained to them, there was an even split between those who felt they were experiencing it and those who felt they were not. The reasons why certain interviewees felt they were not affected by fuel poverty varied considerably, and often centred on the structure of everyday life among such households. For many of them, the active nature of day-to-day movement patterns provided extended periods of time when they did not have 
to use energy services in the home. Such activities provided an important coping strategy for dealing with the significant 'spatial shrinkage' (Shortt and Rugkasa 2007) in the heating of their homes. However, this also meant that the houses were heated in highly variable ways, over time and space alike.

We also detected the presence of a widespread cultural expectation that living in a cold home is 'a normal part of everyday life when you are young'; this is perhaps one of the reasons why none of the interviewees felt 'shame' for not having a warm home (contrary to, for example, Harrington el al's (2004) findings). The lack of reporting of any negative health impacts from living in cold temperatures may also be attributed to the fact that many of the interviewees did not have the impression that they were experiencing a constant exposure to cold temperatures, due to their mobile lifestyles.

In the case of households who felt they were experiencing fuel poverty, the articulation of everyday life was also affected by additional social dynamics, alongside to the conventional questions of income and energy efficiency. Several individuals highlighted the complexities in household relationships: despite paying rent separately, energy bills are collective and therefore, with the household having varying finances, energy use is frequently brought down to a level that can be afforded by the person on the smallest budget. As a result, even those who were relatively well off financially lived in cold temperatures if this was dictated by their household circumstances.

\section{Landlords, housing careers and being 'heard' locally}

The qualitative evidence from the case study area also indicated that wider political and economic relations also affected the constituent dynamics of energy vulnerability. A number of interviewees indicated that their transitory housing tenure made them poorly involved in local politics, and vulnerable to pressure from landlords. Several of them pointed out that they didn't necessarily feel excluded, but instead were just not interested in getting involved in local community activities. There were a number of individuals, however, who located the reasons for the lack of local involvement in the impression that they were not sufficiently capable or knowledgeable, that they wouldn't be listened to, or that they would not be effective in their activities.

Interviewer: If you had an issue, would someone from like the council d o something about it? Becky: I think they would listen but not do anything about it, because like we don't really get taken seriously. I don't really know why people would think like that about us. I think people with more life experience will know more about things, I don't know ... we don't have that much experience and well I know we are living on our owns, but we are still in a bit of a bubble, it is not the same ...

Interviewer: So why don't they put in very much effort?

Helen: I think it is because they think people will just out up with it. I mean I get annoyed by it, but I wouldn't make a complaint to the council or anything. I mean it is quite a lot of effort for a student and we are only here for like a couple of years and it is predominantly students so people are just like 'oh well they are only here for a few years'.

From the interviews it was clear that landlords and estate agents are strongly implicated in the nature of energy consumption. Almost all of interviewees had obtained their homes the through a letting agency, and felt they did not receive very good customer service:

Gemma 1: ... Kelly's ceiling leaked and it was literally like water dripping into her room from the outside every time it rained ... she rang them up and it took them like 3 days to come down. I feel like a lot of estate agents in Selly Oak ... don't take anyone seriously, because everyone is a student and they know that they are not going to do anything. If I ring [estate agent name omitted] up [with a complaint] they will be like 'OK' [sarcasm]. But, if my mum rang up and said you need to do something about it they would do it straight away kind of thing.

In some cases the interviewees felt that they lived in poor quality housing because the landlords knew the houses would be rented by students and young people, who would be unlikely to be very demanding:

Emily: I think they all just see us all as kids still ... they know that people don't actually care that much about where you're living. Everyone just accepts that it is going to be a cold, grimy, disgusting house. 
Victoria: But I think the landlords treat these as student homes and they don't repair things properly, because they know students don't care that much.

There was, however, evidence of good practice. A number of individuals thought that they had a good relationship with their landlords, and that it was only the letting agents that were slow to address problems:

Emma: Yeah we got the heater straight away, but because we didn't realise it was broken until Friday and they couldn't do anything until after the weekend. On Monday it got sorted out straight away.

Brigid: Erm, the landlord we have is actually really nice, we are lucky to have a really good one, because [letting agent name omitted] can be really slow.

The interviewees' comments about the treatment they received by letting agencies highlighted some of the major disadvantages of being a tenant. Some interviewees emphasised that letting agents saw them as 'incompetent and irresponsible', and often failed to provide the necessary information about the quality of the rented house. Still, the efficiency of the housing stock was not considered in many of the interviewees' decisions over their houses. Some of them pointed out that this was particularly true at the point when they entered independent accommodation for the first time - often in the second year of university, having moved out of managed accommodation and halls. Indeed, there is some anecdotal evidence that the average temperature readings in such homes were lower than the rest of the sample, because the interviewees had selected homes that were less energy efficient. Only one interviewee in this group had a good understanding of what to look for in a house, and even discussed the energy certificate it had been given; the data logger results showed that this was the warmest house in the sample.

The experience of living in independent accommodation did seem to improve the majority of interviewees' knowledge of the energy efficiency of the built fabric, heating system, and installed appliances. Many of the interviewees were experiencing another shift in their level of house satisfaction and expectations as a result of this process, and were planning to move, or had already moved, into better quality accommodation once their contract had ended:

Interviewer: Do you think the house will be Ok at keeping the heat?

Rebecca: Well apparently it's quite energy efficient, its rated 'e' or something.

Interviewer: How did you find that out?

Rebecca: We were giving it as part of our contract.

Interviewer: Oh right so you got a rating with it.

Rebecca: Yes.

Interviewer: Who did you go through?

Emily: ... we found it through [company name omitted] ... Basically in terms of energy efficiency, the downstairs, so the living room and the kitchen are energy efficient, but there is no insulation in the loft which is losing heat, but they are putting it in.

Interviewer: Ok, and do you think you have learnt much in like what to look for in a house? And tell me what those things are.

Chris: Like check for like double glazing, and ask people what their boiler is like and ask them what they are paying for bills ... see if it is gas stove or central heating or whatever. Look to see if stuff is new because like new will be more efficient ... like well the girls want a dishwasher but I don't because I think it will use a lot of electricity, plus I would hate unloading it [laugh]. Yeah stuff like that.

Ruth: Well, we are firstly looking at cheaper houses because well like we have got friends... well we have got a really nice house, but there are friends with just as nice houses that are cheaper, we are looking at the size of bedrooms because quite a lot of these ones are quite small ... like we are asking whether the house is cold as to why they are leaving and we are asking about the landlords ... and bathrooms because our bathrooms are really small.

Interviewer: So you talk a bit more, were they not things that you did the last time?

Ruth: No, I mean I think it is just because like you don't really know in the first year, and you just sort of go for whatever.

Jo: I guess, probably when you look in student houses you don't pay attention to things you should be looking for, I mean we did not pay attention at all, like we didn't look to see if it would be warm, I mean I didn't even look at the windows. I think next time I will definitely look at stuff like heating and like good insulation. 
Interviewer: Why didn't you for this one?

Jo: I don't know, when you are with your friends ... we should have really because we have done this for a year already. I think when I leave university I will pay more attention

Almost all of the interviewees expected that they would stay on the same housing career path in the near future. However, they still insisted they knew what they were looking for and that the quality of the home would be of a higher priority in the future. Everyone stressed the importance of flexibility in their living arrangements:

Interviewer: When you moved out what would that be, to rent or buy?

Jessica: Rent

Interviewer: Why rent?

Jessica: I don't know, I just imagine that anything I would have would just be temporary so, I think it is just more... I mean I know it used to be that you would buy, but I think it is more common that you just rent houses now. I mean my cousin now is in her second house and she has a really good job and could buy it but is renting still for some reason.

Interviewer: Right, do you think you will buy?

Jessica: Yes, eventually I would buy.

Throughout our field research, it became abundantly clear that for almost all of the surveyed households, it was the area (Bournbrook) rather than the house that made a difference in the choice of living location. In the desire to be close to work, university or friends, many of them were willing to pay more and live in a poorer quality and energy inefficient home. This would explain why some of the interviewees are experiencing fuel poverty-related problems, also why landlords generally do not improve the quality of the homes. Not only do tenants fail to see this as priority, but there is so much demand that houses of the poorest quality can still be rented out.

\section{Conclusion}

Although the findings reported in this chapter are of a preliminary nature, they provide some broad insights into patterns of domestic energy deprivation among flat-sharing young people living in privately rented accommodation, especially in relation to broader housing and energy consumption issues. The reviewed evidence in the study area has indicated that many of the surveyed households are living in homes whose temperatures are below what is considered an acceptable standard. Many of them, however, do not acknowledge or recognise that they living in this condition. In addition to the poor knowledge of thermal comfort and energy efficiency standards, their situation is, in part, attributable to the widespread cultural expectation that it is acceptable for individuals to live in poorly heated and low quality housing at the entry point of their housing career. This means that, in social justice terms, energy vulnerability among young flatsharing adults is primarily an issue of recognition. Even though this dynamic was shown to be both external and internal to the surveyed individuals, it nevertheless prevented them from fully 'participating in the public realm' and 'unfurling [their] personality's potential in an unforced manner' (Honneth 2004: 351).

In addition to the inadequate knowledge of energy conservation practices and assistance schemes, the emergence of domestic energy deprivation among this group is contingent on a range of specific demographic and housing factors. This includes dynamics internal to the household in situations where bills are shared, as a result of which the level of heat is brought down to the most affordable level. Also of relevance is the constrained and 'niche' nature of the housing market which they occupy, as well as the poor engagement with local politics and communities; this helps increase the power of landlords and letting agencies, and decreases incentives for energy investment. Indeed, most of the individuals who we interviewed lived in poorly-heated and poorly-insulated homes. They were keenly aware of energy conservation practices and tried to bring their bills down in every possible way. The level of energy service (particularly heating) varied dramatically in their homes, both diurnally and across the various spaces of the home. To a certain extent, the fluid nature of housing and everyday mobility practices among them helped address and cope with some of the implications of living in cold homes. It should be noted, however, that these highly temporally and spatially variable energy practices do not lend themselves easily to the binary thinking embedded in current UK fuel poverty and energy efficiency policies. 
The results of this chapter make it obvious that flat-sharing young people moving into private rented accommodation represent a part of society that is invisible to fuel poverty assistance. Their highly restricted and time-concentrated energy use patterns mean concentrating on capital investment in the housing stock itself could help address the problem. While we did find some evidence that landlords were using the LESA to improve the energy efficiency of rental housing, this was limited and patchy. A more formal and stringent set of obligations to act in this direction may prove more useful. Universities, who are distorting the housing market and indirectly creating some of the conditions that have led to this situation also need to take a more pro-active role; not the least given the demonstrated adverse long term health consequences of living in a cold home.

\section{Figure captions:}

Figure 1: Responses to the statement 'I am satisfied with the level of warmth in my home' $(n=309)$.

Figure 2: Responses to the statement 'Our landlord takes care of the house' $(\mathrm{n}=290)$.

Figure 3: Responses to the statement 'The rooms on the top floor are significantly colder' $(n=310)$.

Figure 4: Comparative responses to statements about the presence of double glazing, mould, condensation, and living in fuel poverty $(\mathrm{n}=286)$.

Figure 5: Graph produced from data logger results in 'John's' ${ }^{3}$ living room (red vectors indicate periods of heating use).

Figure 6: Graph produced from data logger results in John's top floor bedroom.

Figure 7. Living room temperatures in one of the houses studied.

\section{References:}

Baker, W., G. Starling and D. Gordon (2003) Predicting Fuel Poverty at the Local Level: Final Report on the Development of the Fuel Poverty Indicator. Centre for Sustainable Energy, Bristol.

Boardman, B. (2010) Fixing Fuel Poverty: Challenges and Solutions. Earthscan, London.

Buzar, S. (2007) Energy Poverty in Eastern Europe: Hidden Geographies of Deprivation. Ashgate, Aldershot.

Clugston, R. M. and W. Calder (1999) Critical dimensions of sustainability in higher education. In Filho, W. L. (ed.), Sustainability and University Life, Peter Lang, New York.

Healy, J. D. and J. P. Clinch (2004) Quantifying the severity of fuel poverty, its relationship with poor housing and reasons for non-investment in energy-saving measures in Ireland. Energy Policy 32, 207-220.

Honneth, A. (2004) Recognition and justice: Outline of a plural theory of justice. Acta Sociologica 47, 351364.

Humphrey, R. and P. McCarthy (1997) High debt and poor housing: A taxing life for contemporary students. Youth and Policy 56, 55-64.

Katz, C. (2004) Growing Up Global: Economic Restructuring and Children's Everyday Lives. University of Minnesota Press, Minneapolis.

\footnotetext{
${ }^{3}$ Original names have been changed to protect anonymity.
} 
Meola, C. and G. M. Carlomagno (2004) Recent advances in the use of infrared thermography. Measurement Science and Technology 15, 27-58.

Nicholson, L. and F. Wasoff (1989) Students' Experience of Private Rented Housing in Edinburgh. University of Edinburgh, Student Accommodation Service, Edinburgh.

Rudge, J. and F. Nicol (eds.) (1999). Cutting the Cost of Cold: Affordable Warmth for Healthier Homes. London: E \& FN Spon.

Rugg, J., D. Rhodes and A. Jones (2000) The Nature and Impact of Student Demand on Housing Markets. York Publishing Services for the Joseph Rowntree Foundation, York.

Slater, T. (2002) Edgbaston: A History. Phillimore, Chichester.

Smith, D. P. and L. Holt (2007) Studentification and 'apprentice' gentrifiers within Britain's provincial towns and cities: extending the meaning of gentrification. Environment and Planning A 39, 142-161.

Walker, G. and R. Day (2012) Fuel poverty as injustice: Integrating distribution, recognition and procedure in the struggle for affordable warmth. Energy Policy 49, 67-75. 